\title{
Tempo e Fotografia: sensibilidades entrecruzadas na cidade de Ouro Preto
}

\section{Time and Photography: sensitivities crisscrossing in Ouro Preto city}

\section{Nara Rúbia de Carvalho Cunha}

Secretaria Estadual de Educação de Minas Gerais

\section{Alexandre Augusto de Oliveira}

Prefeitura Municipal de Jundiaí

\section{Resumo}

Este texto problematiza possibilidades de produção de conhecimentos históricos e educacionais com e sobre registros fotográficos no espaço urbano, considerando o tempo como elemento fundamental para a compreensão desse espaço. Toma-se como mote uma investigação realizada em Ouro Preto (MG), em 2012, no bojo de uma oficina que teve como objetivo a sensibilização do olhar do sujeito para a cidade, muitas vezes tomada como objeto de contemplação cuja historicidade é sublimada. Nesse processo de reelaboração do olhar, a fotografia foi abordada como artefato cultural capaz de intervir na realidade e, portanto, o trabalho foi pautado na reflexão sobre os impactos da fotografia na percepção da cidade de Ouro Preto, tanto como promotora da diluição temporal quanto, num exercício de olhar a contrapelo, como reveladora de amálgamas de temporalidades múltiplas.

Palavras-chave: Ouro Preto; Fotografia; Tempo; Cidade; Educação.

\begin{abstract}
This article problematize the production of historical and educational knowledge with and about photographic registers in the urban space, considering time as the fundamental element for understanding the space. It takes as motto an investigation performed in Ouro Preto (Minas Gerais, Brazil), in 2012. The objective was to raise awareness of the subject's gaze on the city and its multiple temporalities. Photography was approached as a cultural artifact capable of intervening in reality. The work was based on the reflection on the impacts of photography on the perception of Ouro Preto, as a promoter of temporal dilution and as revealing multiple temporalities.
\end{abstract}

Keywords: Ouro Preto; Photography; Time; City; Education. 


\section{Artigos e Ensaios Totografia, Arte e Fistória

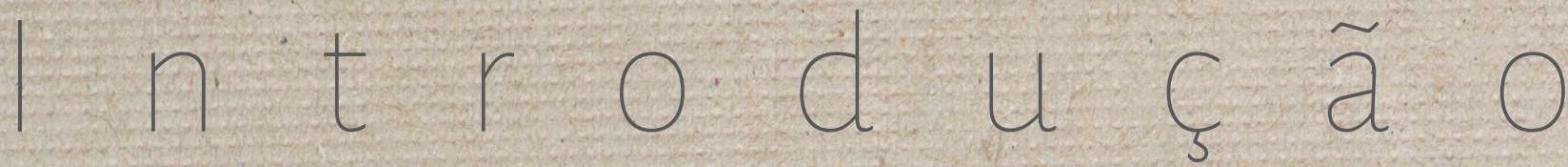

"Desdobram-se as montanhas de Ouro Preto Na perfurada luz, em plano austero. Montes contempladores, circunscritos, Entre cinza e castanho, o ol har domado

Recolhe vosso espectro permanente.

Porigual pascentais a luz difusa Que se reajusta ao corpo das igrejas, Evolve o pensamento à descoberta

De uma luta antiqüíssima com o caos,

De uma reinvenção dos elementos

Pela força de um culto ora perdido,

Relíquias de dureza e de doutrina,

Rude apetite dessa cousa eterna Retida na estrutura de Ouro Preto".

Montanhas de Ouro Preto

Murilo Mendes

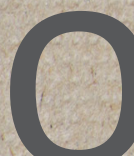

jogo de luzes que opõe claro e escuro, característica do Barroco, e a vocação para a eternidade marcam a imagem da cidade nesse poema de Murilo Mendes, publicado em 1954 no livro Contemplação de Ouro Preto. Ele expressa sensibilidades historicamente constituídas em face da cidade tornada Monumento, em 1933, por influência de Modernistas que buscavam no interior do país a essência da identidade nacional. Tal imagem reverbera em cartões postais e em registros fotográficos que, não raro, dão destaque à cidade colonial e barroca, buscando suspender o tempo - e as ações dos homens no tempo - para entrar na eternidade?

1 Há limites para divulgação dessas obras, em função dos direitos autorais. Recomenda-se que o leitor acesse sites de turismo, tais como Circuito (2018) e o Tripadvisor Brasil (2018), nos quais é possível encontrar, respectivamente, cartões postais virtuais e fotografias produzidas por visitantes. Nesse último há possibilidade de acessar a classificação das preferências dos visitantes por ordém de incidência dos recortes visuais registrados. 
Cartões postais e diversas fotografias de Ouro Preto, comumente focalizando apenas seus monumentos de cultura material e um cenário de antigo idealizado, são as mais correntemente divulgadas, impressas ou em meio eletrônico, e estimulam uma percepção da cidade como algo cristalizado no tempo. Nelas as ruas prescindem dos sujeitos que as constituem como lugar histórico, assim como de suas marcas cotidianas, e a paisagem se torna símbolo de preservação enquanto estagnação do tempo (ANCOTTI-SALCUEIRO, 1996). As percepções da cidade expressam e reforçam, assim, uma contemplação pautada no olhar domado, guiado por discursos que o educam. Nessa educação de formas de ver e perceber a cidade, a fotografia tem tido papel fundamental (OLIVEIRA, 2006).
Cartões postais e diversas fotografias de Ouro Preto, comumente focalizando apenas seus monumentos de cultura material e um cenário de antigo idealizado, são as mais correntemente divulgadas, impressas ou em meio eletrônico, e estimulam uma percepção da cidade comoalgo cristalizado no tempo.

Neste artigo, apresentam-se possibilidades de produção de conhecimentos históricos e educacionais com e sobre registros fotográficos no espaço urbano, tomando-se como mote uma experiência formativa realizada na cidade de Ouro' Preto, em 2012, para tecer considerações sobre o potencial da fotografia para a percepção do tempo como elemento fundamental para a compreensão do espaço (CAUQUELIN, 1982).

O texto está subdivido em partes que propiciam ao leitor acompanhar o contexto de realização de tal experiência formativa, iniciando pela apresentação da construção de uma imagem da cidade de Ouro Preto a ser projetada nacionalmente, aindá, no século XIX e, em seguida, detaIhando a atividade realizada para, ao final, comentá-la e tecer as considerações finais.

\section{A contribuição visual de Ouro Preto para uma pedagogia da nacionalidade}

Entre os anos 1933, data de seu tombamento como Monumento Nacional, e 1980, reconhecimento como Patrimônio Histórico e Cultural da Humanidade, a arquitetura de Ouro Preto passoú por muitas modificações, buscando-se uma imagem de origem, isto é a cidade colonial. 


\section{Artigos e Ensaios Fotografia, Arte e História \\ na atualidade: relações praticadas}

Nessa empreitada, marcas de outras temporalidades foram apagadas ou menosprezadas, consideradas nocivas ao discurso da cidade monumento, símbolo do Barroco Mineiro. A imagem construída induzia à visualização de uma cidade cuja importância ligava-se à mineração, desde fins do século XVII até meados do XVIII, e personagens transformados em referência de cidadania, como o mártir Tiradentes, e de talento artístico, como Aleijadinho.

A historiadora Heliana Angotti-Salgueiro, em texto intitulado Ouro Preto: dos gestos de transformação do "colonial" aos de construção de um "antigo moderno" (1996), partindo da análise das fachadas do casario residencial da cidade, problematiza a construção da imagem colonial de Ouro Preto em detrimento de outras temporalidades. A historiadora se propõe a mostrar o quão eclética é a arquitetura da cidade:

Interessa-me pois demonstrar que o estilo das casas de Ouro Preto se completa no século XIX. Este enfoque sobre a arquitetura de uma cidade que se tornou um mito, significa levar em conta antes os graus de disjunção e as variantes estilísticas do que a uniformidade e a homogeneização artificial de uma historicidade construída pela política patrimonial (ANGOTTI-SALGUEIRO,1996, p. 126).

Outros trabalhos também argumentam sobre a modernização da cidade no século XIX, apresentando, a partir da arquitetura, as transformações sofridas pela cidade antes e durante a condição política de Imperial Cidade de Ouro Preto, a partir de 1823:

A chegada do século XIX marcou definitivamente a Vila, devido às inúmeras transformações, até então inusitadas, que a capital vivenciou. Por um lado, encontrava-se instalado um quadro socioeconômico alarmante devido à decadência da exploração do ouro, já anunciada na segunda metade do século XVIII. Simultaneamente, à medida que novas condições materiais se impunham, Vila Rica submetia-se também aos desafios da modernização, impetrados especialmente com a presença da corte imperial portuguesa no Brasil. A antiga vila, então sede da capitania, foi promovida à condição de capital da Província de Minas Gerais, definindo uma nova fase na sua história (LEMOS, 2006, p. 3).

A condição política da Vila contribuiu para evitar o colapso econômico-populacional. No entanto, as convulsões políticas do século XIX estavam presentes no cotidiano da Imperial Cidade de Ouro Preto, sobretudo a partir da intensificação da campanha republicana.

Após a Proclamação da República, os republicanos procuravam distanciar-se das imagens do Império e da Monarquia, atribuindo a elas o sentido do velho e ultrapassado. No caso da província mineira, a Imperial Cidade de Ouro Preto era algo a ser superado, visto que, enquanto representante do poder monárquico, remetia ao atraso. As elites políticas mineiras, bem como as brasileiras, apostavam no novo, no moderno. 
Naquele momento a modernidade estava na prosperidade da Zona da Mata, acreditava-se; e a ideia de construção da nova capital mineira ganhava força nos debates políticos dentro da província. A definição de um lugar onde construir esta nova capital acompanhou a geografia político-econômica mineira. As cidades de Juiz de Fora, na Zona da Mata, e a própria Ouro Preto, na região mineradora, eram duas fortes candidatas a sede da nova capital.

Na luta por continuar sediando a capital mineira, Ouro Preto não poupou esforços para transformar sua paisagem. A arquitetura da cidade passou, então, por um processo de modernização, incluindo elementos e estilos modernos em seus prédios e fachadas.

Documentos avulsos relativos aos melhoramentos da capital, pertencentes ao Arquivo Público de Ouro Preto, são importantes fontes para estudo dos planos de intervenção na paisagem urbana. Entre eles, encontra-se uma planta arquitetônica de um projeto de Boulevard a ser construído na Barra, um bairro de Ouro Preto (Imagem 1). O desenho apresenta indícios do estilo arquitetônico almejado pelos defensores na modernização urbana da cidade.

Imagem 1 - Planta do Projecto de Boulevard para a cidade de Ouro Preto (1891).

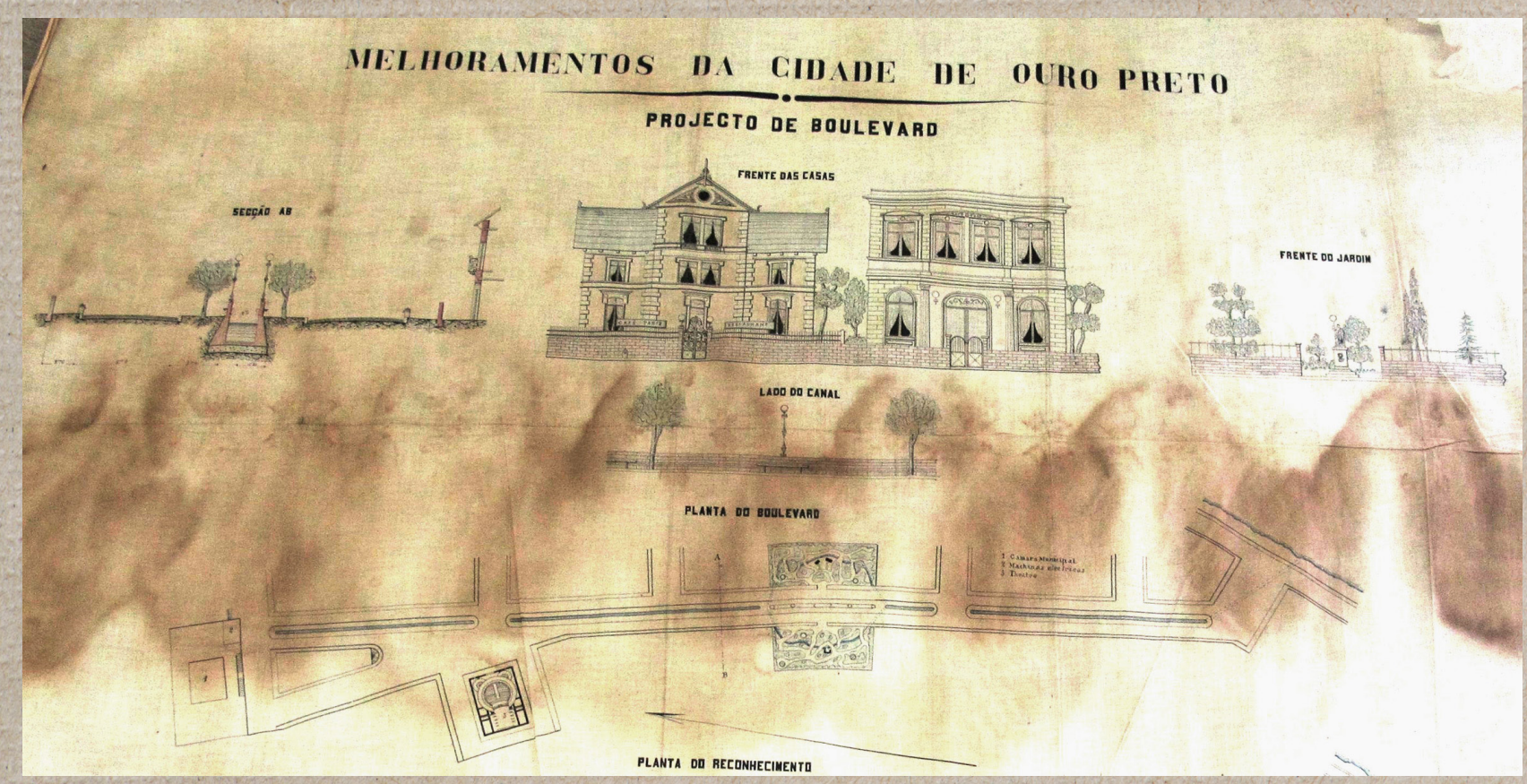

Fonte: Fotografia elaborada pelos autores a partir de documento original de acervo do Arquivo Público Municipal de Ouro Preto (APMOP, 1891).

Uma vez que Belo Horizonte se torna a grande vencedora da disputa e a capital é transferida, Ouro Preto vive um período de abandono, o que potencializa o processo de redefinição da forma como ela é percebida.

'A partir de então, percebe-se uma guinada no olhar sobre a cidade, tingido de uma nova sen- 


\section{Artigos e Ensaios Fotografia, Arte e Fistória \\ na atualidade: relações praticadas}

sibilidade, que passa a vê-la como bonita, pictórica, histórica, digna de preservação. Agora o passado e a história são motivos de preservação. O que conta é a visibilidade da cidade tal como ela se apresenta, uma vez que a arquitetura colonial torna-se o atestado indubitável, o tecido do tempo, a prova legítima e cabal de uma história heróica, de um passado histórico fundamental na construção da identidade do povo mineiro e brasileiro (NATAL, 2007, p. 70).

A imagem colonial, antes vista como símbolo do velho e decadente, é retomada e seus sentidọs são reelaborados, tornando-se referência identitária, remetendo a um passado áureo, de lutas e glória:

Ouro Preto torna-se o teatro dos grandes feitos, dos gestos que marcaram a história, o lugar onde se inscreveu tais acontecimentos, a prova autêntica, visível, de fatos históricos que concorreram para a definição da própria identidade do povo mineiro e brasileiro. Remanescente de um passado heróico, a cidade traz em si as reminiscências de sua história; deve ser vista, portanto, como relíquia, como peça sagrada, lendária, essencial na legitimação da tradição e na construção da identidade de Minas e do país (NATAL, 2007, p. 77).

O historiador Caion Meneguello Natal salienta que a preservação da materialidade de Ouro Preto foi o grande requisito de sua identidade histórica, fazendo sua imagem de guardiã do tempo e das tradições se opor à cidade moderna, símbolo da transformação constante. Nesse sentido, seus prédios deveriam ser capazes de dizer de sua história.

Em 1933 a cidade foi considerada Monumento Nacional e foi revestida de um papel histórico-

Imagem 2-Fotografia Liceu de Artes e Ofícios, de Luiz Fontana (por volta de 1940).

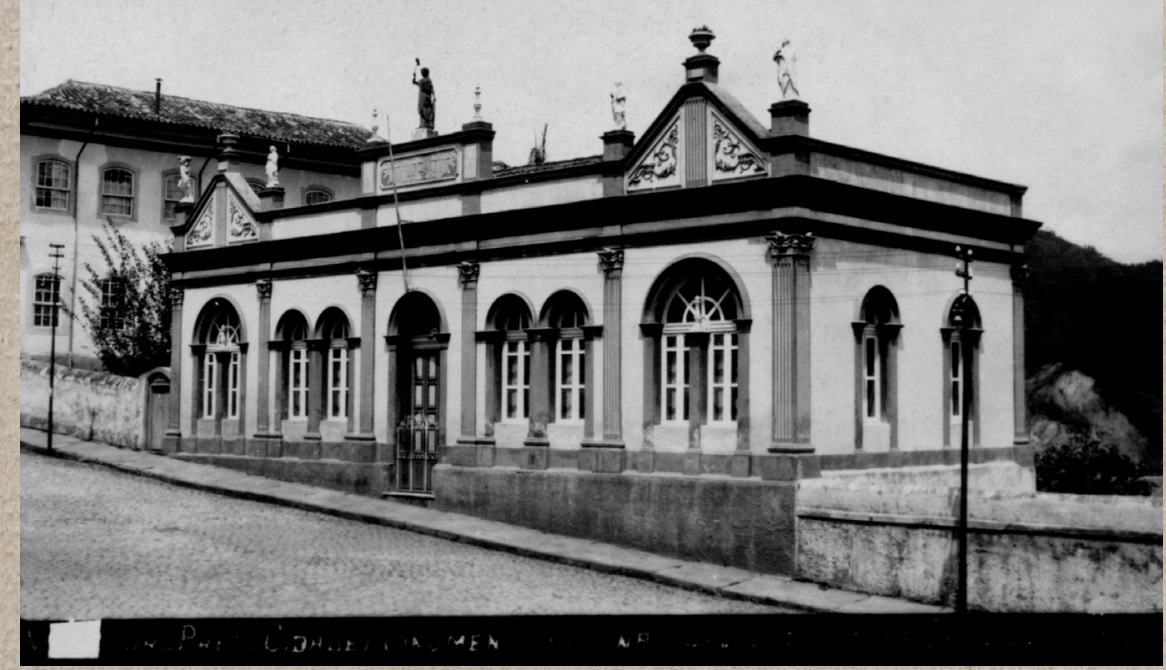

Fonte: Acervo do Arquivo Público Municipal de Ouro Preto - Coleção Luiz Fontana (FONTANA, 194-). -pedagógico fundamental para o país: "construir uma memória comum, de modo a criar uma pedagogia da nacionalidade" (ANASTASIA, LEMOS \& JULIÃO, 1999, p. 132). A partir desse momento, intensificam-se as práticas de intervenção na paisagem, como pode ser exemplificado com o antigo Liceu de Artes e Ofícios (Imagem 2), atual Cine Vila Rica, na Praça Reinaldo Alves de Brito, em Ouro Preto. 
A fotografia de Alexandre Augusto de Oliveira (Imagem 3) permite visualizar as intervenções no prédio do antigo Liceu de Artes e Ofícios, como a retirada das platibandas que ocorreu na década de 1960 por iniciativa do SPHAN, e construções feitas posteriormente ao registro do fotógrafo Luiz Fontana, na década de $1,940$.

Paralelamente às intervenções para retirada de elementos que se afastavam da imagem coIonial da cidade, investe-se em ações educativas que auxiliem na compreensão dos sentidos conferidos à cidade monumento. Diversos projetos educativos começam a ser desenvolvidos, sobretudo a partir de 1970 , enfocando principalmente os aspectos materiais da cultura. Eles colaboravam com a educação de sensibilidades voltadas para a apreciação, preservação, contemplação da cidade. Alguns, inclusive, se empenhavam por fomentar também sensibilidades mais ligadas ao cotidiano dos moradores, aos costumes locais, às memórias plurais, como é o caso do Museu-Escola do Museu da Inconfidência (CUNHA, 2011).

\section{Imagem 3 - Fotografia Perspectiva do Cine Vila Rica, de Alexandre Augusto de Oliveira (2016).}

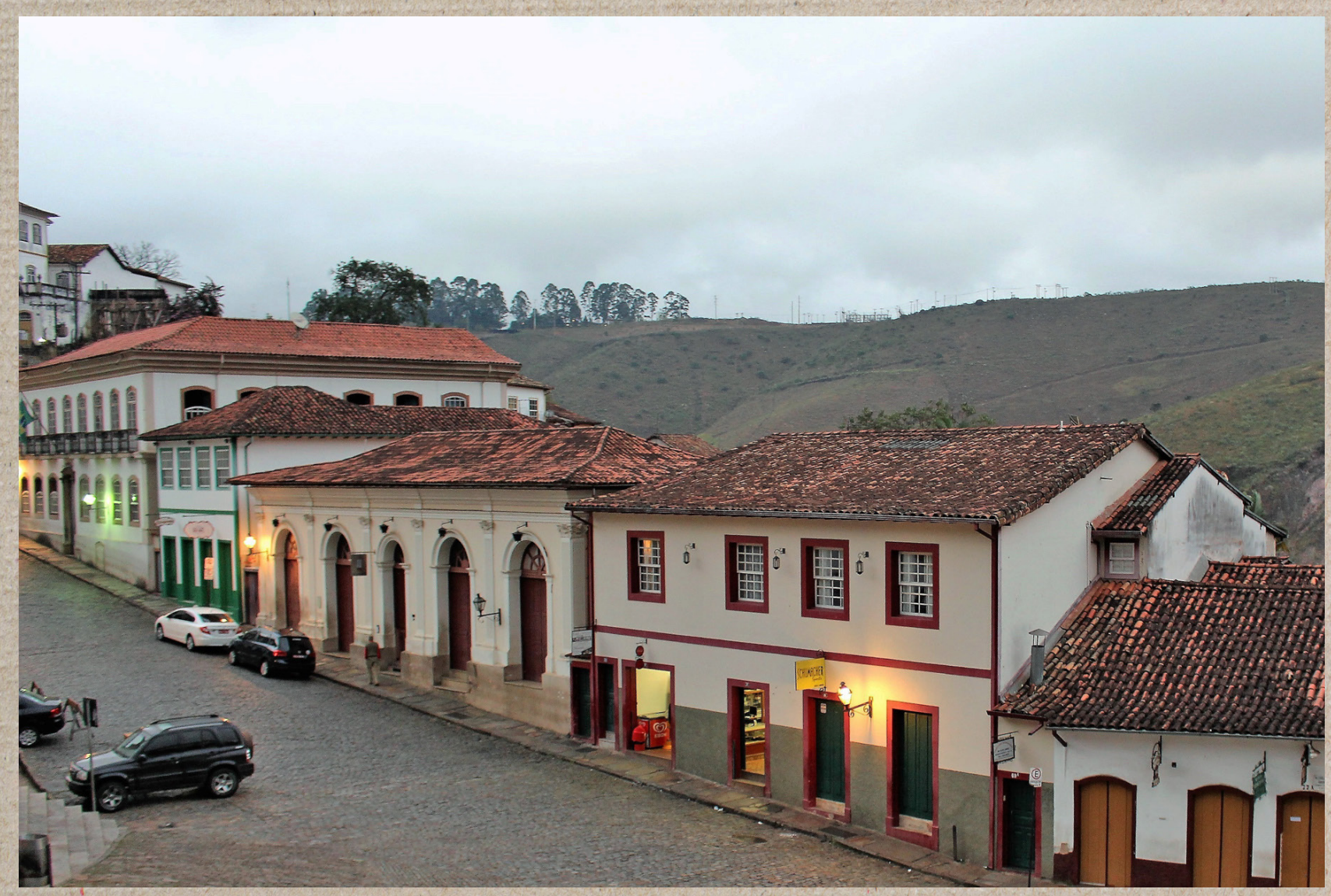

Fonte: Acervo pessoal do coautor

Paralelamente às intervenções para retirada de elementos que se afastavam da imagem colonial 'da cidade, investe-se em ações educativas que auxiliem na compreensão dos sentidos 


\section{Artigos e Ensaios Fotografia, Arte e História \\ na atualidade: relações praticadas}

conferidos à cidade monumento. Diversos projetos educativos começam a ser desenvolvidos, sobretudo a partir de 1970, enfocando principalmente os aspectos materiais da cultura. Eles colaboravam com a educação de sensibilidades voltadas para a apreciação, preservação, contemplação da cidade. Alguns, inclusive, se empenhavam por fomentar também sensibilidades mais ligadas ao cotidiano dos moradores, aos costumes locais, às memórias plurais, como é o caso do Museu-Escola do Museu da Inconfidência (CUNHA, 2011).

No entanto, a despeito de alguns esforços, no amálgama de sensibilidades presentes na construção de formas de ver e sentir a cidade, algumas se sobressaíram como tendências dominantes, favorecendo o apagamento de memórias e de experiências plurais, sobretudo quando se considera a ação de uma engenharia cultural que potencializa a conversão da cidade em mercadoria.

Cidades monumento, como Ouro Preto, não têm apenas a dimensão de documentos ou centros de fruição estética. Elas são, em grande parte das vezes, transformadas em mercadorias, tendo seu valor de uso suplantado pelo valor econômico.

A metamorfose de seu valor de uso em valor econômico ocorre graças à 'engenharia cultural', vasto empreendimento público e privado, a serviço do qual trabalham grande número de animadores culturais, profissionais da comunicação, agentes de desenvolvimento, engenheiros, mediadores culturais. Sua tarefa consiste em explorar os monumentos por todos os meios, a fim de multiplicar indefinidamente o número de visitantes (CHOAY, 2006, p. 211).

Assim, quando se procura tomar a cidade de Ouro Preto como espaço de produção de conhecimentos históricos e educacionais, convém que se questione sobre quantas cidades não contempladas, negligenciadas e colocadas à margem convivem à sombra desse Monumento.

Se por um lado a fotografia, comercializada em forma de cartões postais, pode ser vista como elemento fundamental da engenharia cultural que transforma a cidade em mercadoria, por outro, ela abre possibilidades de uma relação mais próxima e atenta aos detalhes, visto que a máquina pode ir aonde o olho, em certos casos, não alcança ou nã̇o está habituado a perceber. Neste sentido, quando colocada a contrapelo das tendências, a fotografia pode favorecer a percepção de múltiplas temporalidades que convivem na cidade de Ouro Preto, na contemporaneidade.

Tomando essas premissas como norteadoras, como parte integrante de uma pesquisa-ação desenvolvida com professores em Ouro Preto, no ano de $2012^{2}$, foi elaborada uma oficina tendo

2 Pesquisa-ação "Primaveras Compartilhadas", desenvolvida em pesquisa de doutorado na Faculdade de Educação da Unicamp (CUNHA, 2016). 
a fotografia como elemento primordial de questionamento de sensibilidades historicamente engendradas (GAY, 1988), de busca de memórias que permitissem ampliar as possibilidades de olhar diferentes temporalidades que marcam a cidade, enfocando o tempo presente.

\section{Fotografias de Ouro Preto: da estagnação aos estilhaços do tempo}

A oficina ocorreu a convite do grupo Primaveras Compartilhadas, formado por professores de Educação Básica de Ouro Preto que participavam de um processo formativo que tomava a cidade, suas memórias e paisagens, como meio de reflexão, a fim de reelaborarem possibilidades de interação pessoal e educativa com a mesma.

Tal grupo foi organizado no contexto de uma pesquisa de formação docente, realizada junto ao Grupo de Estudos e Pesquisas em Educação Continuada (CEPEC), da Faculdade de Educação da Unicamp, e ao grupo de pesquisas Kairós: educação das sensibilidades, história e memória, sediado no Centro de Memória dessa mesma instituição. E, em Ouro Preto, o Primaveras Compartilhadas estabeleceu parceria com o Museu Casa Guignard, tomando-o como ambiente e inspiração para essa pesquisa-ação em várias oficinas que ocorreram dentro do projeto, como a oficina de fotografia.

Imagem 4 - Frente do Cartão Postal enviado por Guignard a Lúcia Machado de

A reflexão sobre a fotografia foi orientada pelo historiador e mestre em Artes Alexandre Augusto de Oliveira. Para problematizar as formas de ver a cidade, ele partiu de um cartão postal que integra do acervo do Museu Casa Guignard (Imagens 4 e 5). Almeida, por ocasião de seu aniversário (1958).

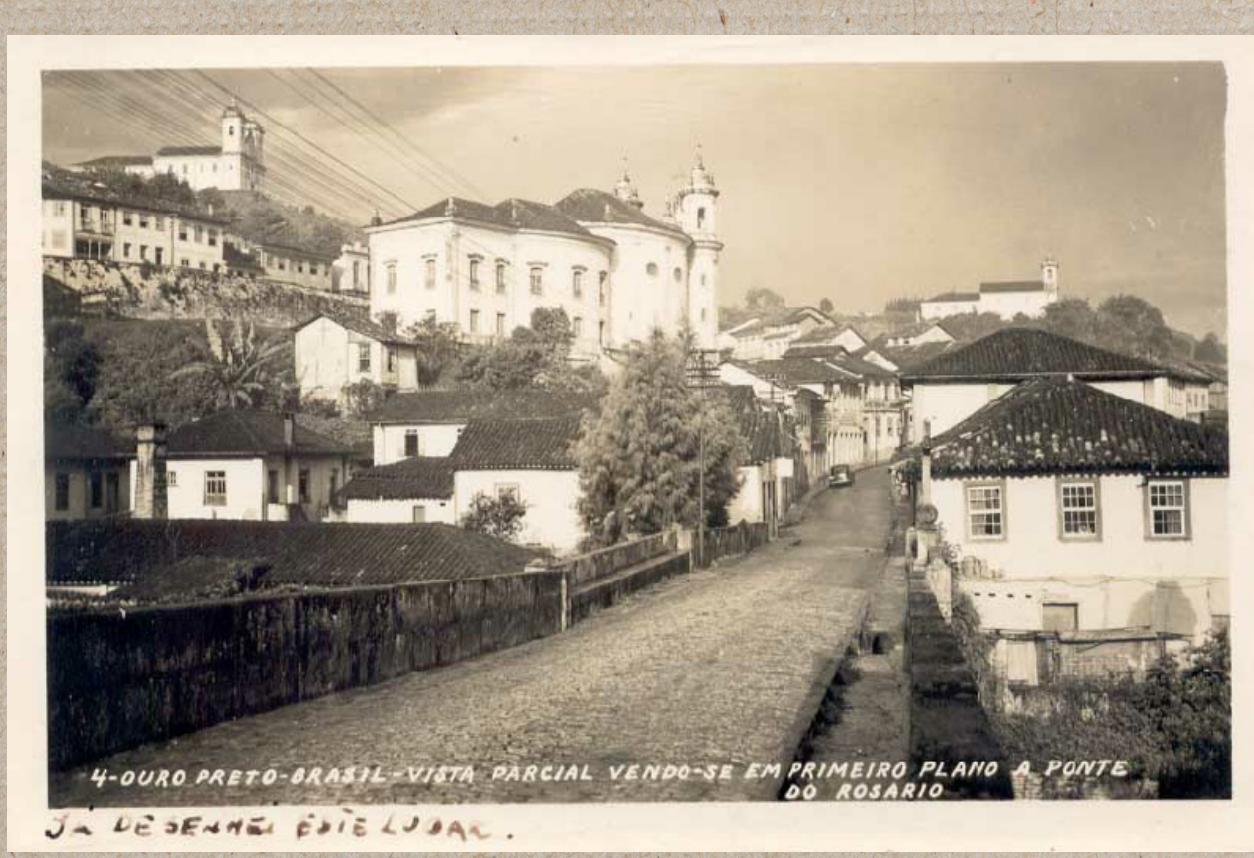

Fonte: Acervo Museu Casa Guignard (PROJETO GUICNARD; 2018a). 


\section{Artigos e Ensaios na atualidade: relaçóes praticadas}

Imagem 5 - Verso do Cartão Postal enviado por Guignard a Lucia Machado de Almeida (1958).

MUITO PREZADA DONA LUCIA!

ESTOU FESTE TA NDO AQUI HODE AS MINHAS GZ, PRIMAVERASEM MEIOEMTRE 30 DE.SENHOS LूA FEITOS. TIVE UMAA HOA NOTICIA DE AN NIVER SARIO VO RE CEBER..... SO O CONTOS NÁ̃ E' MENTIRA NAO VEM DA EURDPA. OTAL"MALANDRD, DE FADRAGTO FOI OPERADO EM GRAVE ESTADO .... FICANDO COM A MEMORIA UM POUCO BASTANTE COM "REMOR SOS. E.... VEN DEU MINAA PARTE DE JM TERRENBPERJO DE GRA SSE QUE ME VAE DAR ESTA SOMMA. TA'ESIÁ ENCAMINHAOO COMIO CONAULADO FRANCEZ ATE RIOI PRETEN DO ENTAOO COMPRAR UMA TERENO AQUIELONS TRUIR MEU "HOME D'ARTISTA "QUETAL. POR PROPOSTA DE SYLVIO VASCOIV CELLA YOU ENTRAR COMMO PROFESSOR CATHEDRATICO NA ESCOLA DEARCHITEC TURA DE B EWO-HORIZONTE,.... ENFIM A MINHA ..... ESTRELAESTÁ..... BEILHANDO....??? REST. SAUDACG ES TAMBEM A ANTONIO VOSSO SEMPRE

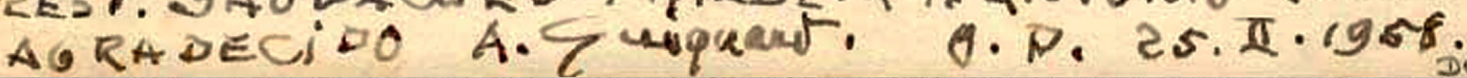

Fonte: Acervo Museu Casa Cuignard (PROJETO CUIGNARD, 2018b).

A fotografia que compõe esse cartão postal é do fotógrafo ouro-pretano Luiz Fontana, sendo do próprio fotógrafo a legenda escrita à mão, sobre a imagem. No canto esquerdo do cartão, fora do campo da imagem, há uma anotação de Guignard, feita em 1958: Já desenhei este lugar, enquanto no verso o pintor escreve um bilhete para a amiga Lucia Machado de Almeida, a quem presenteia com o cartão postal por ele escolhido.

Essa peça do acervo do Museu Casa Cuignard delineia percepções de sujeitos que retrataram a cidade em meados do século XX: Fontana com a fotografia e Guignard com a as artes plásticas. O registro manuscrito de Guignard no postal dá indícios, assim como a escolha do cartão enfocado, de um entrecruzamento de olhares, isto é, de visualidades e sentimentos por Ouro Preto, de Guignard e Fontana.

Luiz Fontana foi, durante muitos anos, o único fotógrafo residente em Ouro Preto (provavelmente durante as décadas de 1930 e 1940). Das milhares de chapas feitas por ele, parte delas (cerca de 1500 fotografias em preto e branco) se encontra reproduzida no Núcleo de Mentalidade e Memória do Instituto de Filosofia e Artes da Universidade Federal de Ouro Preto (IFAC/ 
UFOP). A produção fotográfica de Luiz Fontana é um objeto de estudo instigante por seu número e expressividade, sendo comum encontrar fotografias de um mesmo lugar tiradas em diferentes períodos e perspectivas, o que denota seu cuidado ao compor o espaço nas fotografias.

As reproduções de suas fotografias são documentos visuais importantíssimos para o estudo de transformações urbanas de Ouro Preto e da vida social de seus moradores no século XX. Ao retratar também a vida social da cidade, em procissões e eventos cívicos, a produção de Luiz Fontana deixa marcado o espaço da cidade como uma confluência de experiências individuais e coletivas. Assim, pela visualização de suas fotografias, apreendem-se múltiplas temporalidades sociais presentes no espaço urbano de Ouro Preto, na primeira metade daquele século (OLIVEIRA, 2006).

Por sua vez, Alberto da Veiga Cuignard, um dos mais importantes pintores modernistas brasileiros, nasceu em Nova Friburgo, em 1896, morou na Europa dos 11 aos 33 anos e regressou ao Brasil na década de 1920 , aqui permanecendo até a sua morte, na cidade dé Belo Horizonte, em 1962. Durante esse período, hospedava-se em hotéis ou em casas de amigos e nutria o sonho de ter uma casa em Ouro Preto, a por ele chamada cidade amor, inspiração. O artista contribui com singular sensibilidade para a tessitura de um histórico de construção da identidade cultural brasileira. Em especial, ele destacou sujeitos e cotidianos marginalizados e ressaltou o lirismo da vida no interior, através da divulgação de seus costumes e de suas paisagens repletas de balões, festas, flores e santos de devoção popular.

a obra de Guignard, ainda tão pouco explorada por nossas instituições artísticas e educacionais, pode oferecer um novo prisma no que tange a uma identidade genuinamente brasileira (ainda que diversa e não excludente em relação a tantas outras manifestações artísticas nacionais) no painel artístico pictórico moderno nacional. Esta identidade, retratada nas imagens que reúnem o povo; as festas, a religiosidade e a paisagem montanhosa típica das regiões históricas de Minas, tem hoje o poder de lançar o "contemplador" num estado de aspiração ou desejo de um tempo-espaço que partindo daquele experimentado em tais lugares (Minas histórica/ Minas montanhosa) o transcende, à medida que se reconstrói idealmente na sua imaginação poética (BOTELHO, 2014, p. 3).

A paisagem é destacada por vários críticos como um importante gênero pictórico na obra de Guignard, destacando-se as paisagens mineiras. No livro Guignard: depoimento, organizado por Fernando Pedro da Silva, Marília Andrés Ribeiro e Jaqueline Prado, o crítico de arte Flavio de Aquino afirma que "a paisagem mineira, com Guignard, adquire novo estilo e expressão. Ele 


\section{Artigos e Ensaios Totografia, Arte e História \\ na atualidade: relações praticadas}

a traduz de duas maneiras: uma naturalista e a outra imaginária" (SILVA, RIBEIRO \& PRADO, 2015, p. 27).

Em suas obras Guignard aproxima o observador do cotidiano da cidade, ressaltando os costumes das comunidades locais que o recebiam, como, por exemplo, na série de Vasos de Flores ou nas Naturezas Mortas, em que insere os objetos em uma cena cotidiana, como parte da vida doméstica, e traz, indiretamente, os sujeitos com seus desejos e intervenções na relação com a paisagem. Os sujeitos, portanto, transformavam materialmente essa paisagem. Em outra via, seus retratos e autorretratos inovam por trazerem a paisagem como pano de fundo, claramente ambientando o sujeito retratado.

Na série de Paisagens Imaginantes ou Imaginárias, o artista utiliza uma perspectiva que distancia o observador da coisa observada, conferindo a ele outra visão. Ele liberta os sujeitos de sua própria paisagem, dando-Ihes uma posição elevada e um olhar onírico sobre o cenário em que vivem ou observam.

De acordo com a pesquisadora Taisa Helena Pascale Palhares (2010), a paisagem nas obras de Guignard é mais do que um gênero pictórico, ela é tratada como um problema moderno. Há uma ambiguidade entre interioridade e mundo exterior em Cuignard, em cujas obras a paisagem se reveste também dos olhos de quem a vê.

Como a obra desse artista está quase inteiramente em mãos de colecionadores particulares, não foi possível encontrar o desenho ao qual ele faz referência, quando envia o cartão postal à sua amiga, a escritora Lúcia Machado de Almeida. Desta forma, a oficina procedeu com a análise de um dos destaques de sua obra que compõe a exposição permanente do Museu Casa Guignard, em Ouro Preto.

a tela reproduzida a seguir (Imagem 6), feita em 1947 sob encomenda do governo de Minas Gerais, Guignard coloca no mesmo plano diferentes temporalidades, fazendo conviver em único espaço o passado, o presente e o futuro, este último projetado entremeio a montanhas e igrejas, essas quase tão expressivas quanto aquelas.

Como encaminhamento metodológico da oficina, partia-se da observaçã̀o atenta aos detalhes das obras de Luiz Fontana e de Guignard para promover uma reflexão sobre a relação entre o observador e a paisagem. Como os artistas viam a paisagem urbana? Quais eram os condicionantes dessa forma de ver? Como, na atualidade, os participantes da oficina (professores e moradores locais) viam a cidade? O que poderia estar condicionando essa forma de ver? 
Imagem 6-Reprodução fotográfica da tela Paisagem Imaginária de Minas, de Guignard (1947).

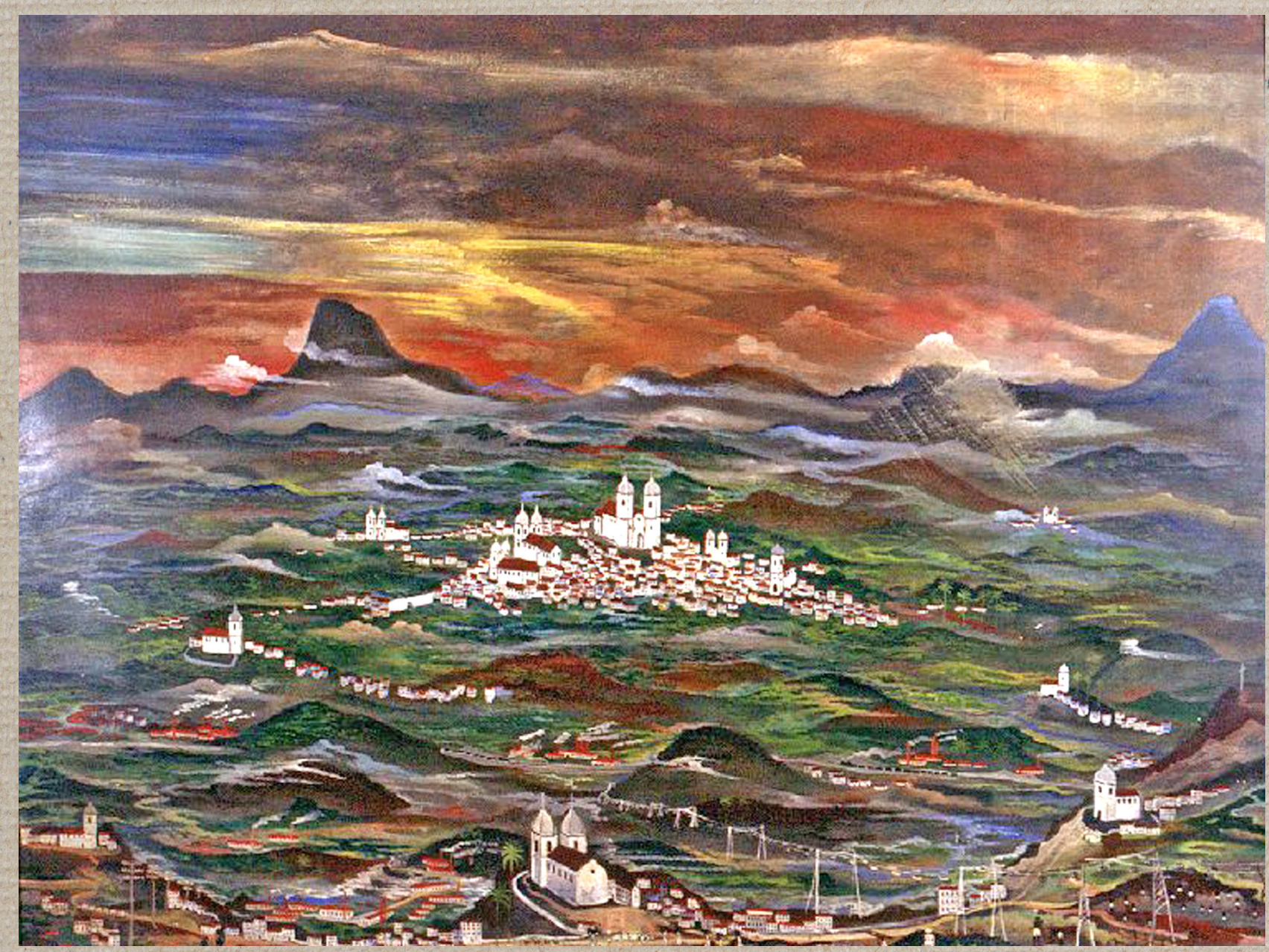

Fonte: Acervo Museu Casa Guignard (PROJETO GUICNARD, 2018c).

A oficina integrava uma série de estudos e atividades que já eram desenvolvidas desde o início da pesquisa-ação Primaveras Compartilhadas. Esperava-se que os participantes adensassem reflexões e indagações iniciadas anteriormente sobre os impactos das transformações físicas das cidades na percepção do tempo e do espaço e nas relações sociais (BENJAMIN, 1995; 2006). E se esperava, sobretudo, que avançassem discussões sobre as mudanças na forma de percepção humana potencializadas pelas inovações técnicas (BENJAMIN, 1994).

Assim, no exercício de abordagem da fotografia de Luiz Fontana e na tela de Cuignard, primeiramente se buscou a visualização da estratificação do tempo no espaço urbano de Ouro Preto, tomando a linguagem fotográfica como suporte para a compreensão da cartografia sentimental desse espaço, conforme apreendido na produção dos dois artistas. Em seguida, buscou-se promover a ampliação dos olhares dos próprios sujeitos do Primaveras Compartilhadas, em relação às imagens enfocadas e à própria cidade, na atualidade. 


\section{Artigos e Ensaios Totografia, Arte e História \\ na atualidade: relaçóes praticadas}

Em seguida, a máquina fotográfica, aliada à percepção humana, foi tomada como elemento capaz de propiciar outras visões (BENJAMIN, 1994), outras perspectivas que evidenciassem camadas de tempo ou memórias preteridas em função do estímuloà construção da imagem colonial da cidade.

Foi proposto que os registros fotográficos a serem produzidos tivessem como referências visuais as obras de Guignard ou Luiz Fontana, analisadas no primeiro momento. Os percursos ou pontos de observação seguiriam o mapa folder Passos de Guignard, elaborado por Célcio Fortes, artista plástico e diretor desse Museu, uma vez que aborda pontos estratégicos de contemplação da cidade, nos quais se articulam na paisagem os aspectos arquitetônicos e as experiências cotidianas de seus moradores. Além disso, esperava-se que retratassem elementos da modernidade presentes no espaço urbano da cidade.

O objetivo desses delineamentos na composição das fotografias era matizar a contraposição entre antigo e moderno no espaço urbano de Ouro Preto, usando como referência olhares que se esforçaram pordarvisibilidade a tais matizes, sem perder de vista que os sujeitos que olham, observam, contemplam, estão imersos nesse ambiente e, portanto, têm suas sensibilidades formadas por e nele.

\section{Camadas de tempo no espaço urbano}

Desde os primórdios da fotografia, o cenário urbano foi tema recorrente de reflexões filosóficas, das quais se destaca um novo ol har sobre a cidade, emergindo desde meados do século XIX, que documentava as transformações da vida urbana (MONDENARD, 1999; BENJAMIN, 1994).

A fotografia, entre olhares críticos e entusiastas, acaba sendo reconhecida como uma arte moderna, ligada à técnica, com potencial para ampliar o alcance do ol har humano:

Mas ao mesmo tempo a fotografia revela nesse material os aspectos fisionômicos, mundos de imagens habitando as coisas mais minúsculas, suficientemente ocultas e significativas para encontrarem um refúgio nos sonhos diurnos, e que agora, tornando-se grandes e formuláveis, mostram que a diferença entre a técnica e a magia é uma variável totalmente histórica (BENJAMIN, 1994, p. 94-95).

Mais do que documentar (no sentido restrito de ser prova da realidade), a fotografia permitia intervir na realidade, permitindo que outras percepções pudessem vir à tona. Ainda sobre o século XIX, Mondenard (1999) ressalta que havia, além do caráter documental, uma dimensão artística nas fotografias, pois proporcionavam uma nova visualização das formas do cenário urbano e a apre- 
ensão de aspectos da vivência de grupos marginalizados - o grande contingente de trabalhadores oriundos do meio rural que, na segunda metade do século XIX e início do XX, viviam em precárias condições nas grandes cidades europeias.

As inovações técnicas e a industrialização tornaram possível a fotografia, servindo esta como registro das transformações decorrentes desse processo. Ao mesmo tempo, a fotografia criou espaços para visualização dessa nova conjuntura histórica. Pode ser citado nesse sentido o trabalho de Jean-Claude Lemagny (1999) que, ao fazer um mapeamento da produção fotográfica, cujo tema é o espaço urbano (o texto focaliza principalmente Paris), propõe ver a cidade pelo prisma da fotografia, sendo o espaço urbano visto de forma desumanizada, frequentemente. O autor destaca como a vivência social condiciona a apreensão da realidade histórica vivida pelo fotógrafo.

Contudo, as imagens fotográficas apresentam algumas especificidades, por isso devem ser analisadas articulando os diferentes níveis de estruturação em que se encontram inseridas, possibilitando ao sujeito cognoscente decompor as mediações do real (KONDER, 1985).

Dessa forma, a definição de uma metodologia específica para analisar as fotografias tem por finalidade desvendar as mediações da imagem fotográfica (o trabalho do fotógrafo, os meios de veiculação da imagem e seus usos, a recepção por diferentes olhares) e decompor as realidades presentes nesse registro (KOSSOY, 2000). A fotografia apresenta duas dimensões do real: uma primeira realidade, que é a própria imagem materializada em um tipo específico de suporte e uma segunda realidade, 0 aspecto do real registrado na fotografia.

Deve-se destacar que a ideia de verdade atribuída pelo senso comum à fotografia se deve ao caráter técnico da imagem fotográfica. Entretanto, as propriedades analógicas da fotografia podem ser relativizadas uma vez que o ato fotográfico é também condicionado pela subjetividade, pois o fotógrafo ocupa um lugar social a partir do qual tem um campo de possibilidades para efetuar o registro. Dessa forma, "a lógica do presente (contemporâneo à feitura) impõe-se-lhe pela própria impossibilidade do homem escapar à rede simbólica que preside o momento que vive" (VIDAL, 1994).

Assim, ao analisarmos as fotografias devemos compreendê-las na sua dimensão de construção cultural e registro do real, pois "o binômio testemunho/criação encontra-se individualmente amalgamado na imagem fotográfica" (KOSSOY, 2012).

Entretanto, tão importante quanto estabelecer uma metodologia adequada para análise das fotografias, é preciso ter consciência das suas limitações. A fotografia é sempre um ato fragmentário, poís não capta inúmeras realidades também presentes no momento do registro. Além disso, a 


\section{Artigos e Ensaios na atualidade: relaçóes praticadas}

imagem fotográfica rompe com o tempo do referente e instaura outra(s) temporalidade(s), trazendo dentro de si uma infinidade de outras imagens, vivências rememoradas e projetadas a partir da sua visualização.

No contexto da oficina desenvolvida em 2012, vários registros fotográficos incidiam sobre o delineamento proposto, provocando nos participantes um olhar mais sensível sobre o cotidiano da cidade atual, na qual pulsa a vida cotidiana e o instante efêmero, ao mesmo tempo em que permitem romper com o presente, abrindo a percepção para outras temporalidades.

Um dos registros trouxe significativa contribuição, uma vez que conseguiu captar experiências que remetem à diversidade de camadas de tempo que se sobrepõem no espaço da cidade.

Explorando uma perspectiva próxima à da fotografia daquele cartão postal enviado por Cuignard, Cattleya, pseudônimo adotado pela docente participante da oficina, registrou um momento no qual um caminhão e dois cavalos transitavam na rua, simultaneamente (Imagem 7). No conjunto estão as igrejas Nossa Senhora do Rosário e São Francisco de Paula, mais ao fundo, e o casario colonial agregando elementos mais modernos. A engenhosidade de um caminhão e a lembrança da dependência do transporte animal, que até poucas décadas atrás era um importante meio de transporte, completam o conjunto.

A fotografia em questão não se enquadra na perspectiva de uma foto com valor de mercadoria, não se preocupa em emoldurar a cidade de Ouro Preto numa aura barroca imóvel no tempo. Ela

Imagem 7 - Fotografia Vista parcial de Ouro Preto, de Cattleya (2012).

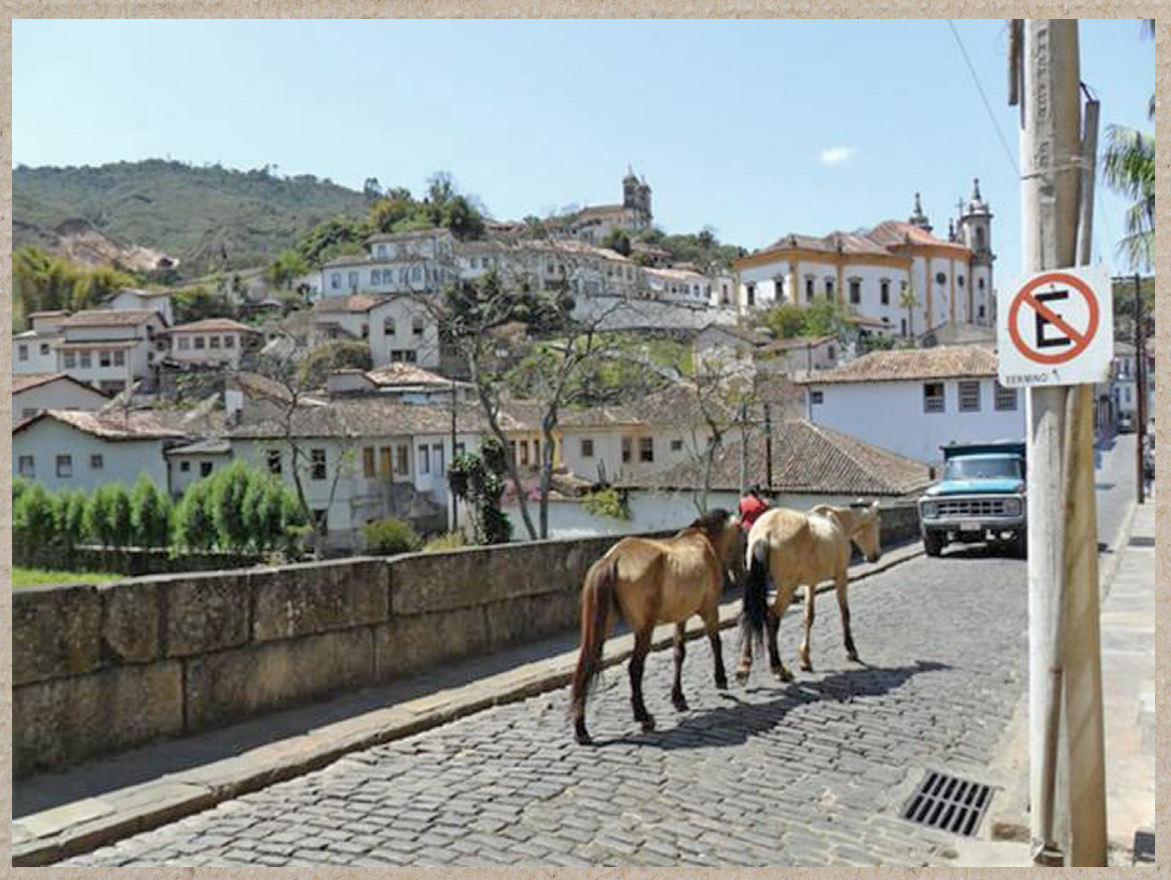

Fonte: Acervo Primaveras Compartilhadas. Coleção particular. deixa irromper várias camadas de tempo que compõem as memórias da cidade.

A contrapelo das tendências dos cartões postais, aqui se emprega outro exercício de sensibilidade para a apreensão da cidade. Camadas de memórias e historicidades superpostas nesses registros desvelam olhares com múltiplas temporalidades que se entrecruzam no espaço urbano. Deixa-se que a contemplação de sua arquitetura seja atravessada 
por outros elementos, outras experiências, outras memórias. Flagra-se, no mesmo instante, um automóvel que transita ao lado de animais, também utilizados para o transporte de pessoas e cargas, em um passado recente.

Uma fotografia como essa não se limita ao ol har domado; ela rompe com sensibilidades historicamente engendradas e que têm favorecido o apagamento de memórias plurais (GALZERANI, 2008). É um exercício a contrapelo das tendências (BENJAMIN, 1994), sobretudo no campo de produção de conhecimentos históricos e educacionais e em práticas de educação patrimonial, muito comuns em cidades Monumento, como Ouro Preto.

Por outro lado, ela também permite a compreensão da constituição do espaço urbano intimamente atrelado e essas camadas de tempo, não simplesmente sobrepostas ou convivendo lado a lado, mas como algo essencial, de onde se constrói um repertório de experiências, com as quais se reinventa a permanência nesse espaço (CAUQUELIN, 1982).

Para a filósofa francesa Anne Cauquelin, a cidade se edifica no e com o tempo. Por isso, a consideração do tempo, ou melhor, das temporalidades e de diferentes acepções de tempo, é condição fundamental para a apreensão do espaço urbano. Para a autora, a cidade é vivida como tempo da velocidade, da destruição e da reconstrução. Assim, a percepção da cidade é afetada por diferentes ritmos e é carregada de resíduos de outros tempos que compõem o viver urbano: "com os traços materiais subsistem memórias gestuais, comportamentos diversos, frequentemente devedores de diversas e sucessivas camadas culturais" (CAUQUELIN, 1982, p. 18) ${ }^{3}$.

Nessa oficina, a fotografia permitiu a percepção da cidade não apenas como cenário, muitas vezes alheio a elementos temporais atados ao presente. Os participantes, ao serem incentivados a contraporem sua apreensão visual dos espaços às imagens de Guignard e Fontana, puderam perceber mudanças e permanências, favorecendo uma maior acuidade na apreensão do espaço urbano de Ouro Preto. Assim, foi favorecida a percepção de que tal espaço não é simplesmente um cenário, mas sima materialização da vida social, com seus contrastes e paradoxos, num amálgama de temporalidades.

\section{Considerações finais}

Este artigo buscou refletir sobre as potencialidades do trabalho com a fotografia na produção de conhecimentos histórico-educacionais.

3 Tradução livre a partir do original: "Avec les traces matérielles subsistente des mémoires gestuelles, des comportements divers, solvente redevables à plusieurs strates culturelles successives". 


\section{Artigos e Ensaios Totografia, Arte e História \\ na atualidade: relações praticadas}

A oficina dialogou com a fotografia e a empregou em seus encaminhamentos metodológicos com o objetivo de contribuir com a reflexão sobre a constituição sobre sensibilidades urbanas, priorizando a percepção do elemento temporal imbricado no espaço e vice-versa, o que muitas vezes é marginalizado nas imagens correntes de cidades históricas e que vão se tornando uma' mercadoria, como é o caso de Ouro Preto.

Se na contemplação dessa cidade as sensibilidades prevalecentes estão mais atadas ao antigo idealizado do que à percepção do novo, ou melhor, do presente e das múltiplas camadas de tempo que o compõem, o trabalho com as fotografias permitiu que fossem abertas discussões sobre temporalidades e memórias plurais, questionando apagamentos e silenciamentos, contribuindo, assim, para que os participantes da pesquisa-ação pudessem ressignificar suas experiências pessoais e educativas na Cidade Monumento.

No entanto, um exercício dessa natureza não se limita a cidades monumento ou ditas históricas. Cotidianamente, em quaisquer centros urbanos, há uma liquidação de referências temporais diversas em detrimento da construção incessante do novo. O trabalho com as fotografias, conforme aqui defendido, tem o potencial de permitir que sejam trazidas à tona realidades, marcas, sujeitos, memórias e experiências marginalizadas, preteridas, ocultadas. A fotografia pode, assim, ajudar o homem, com sua técnica, a ver o mundo de forma ampliada e a ampliar as suas possibilidades de nele atuar de forma mais ética e responsável.

\section{Referências}

ANASTASIA, Carla Maria Junho; LEMOS, Carmem Silva; JULIÃO, Letícia. Dos bandeirantes aos modernistas: um estudo histórico de Vila Rica. Oficina do Inconfidência, Ouro Preto, n. 0, dez. 1999.

ANCOTTI-SALCUEIRO, Heliana. Ouro Preto: dos gestos de transformação do "colonial" aos de construção de um "antigo moderno". Anais do Museu Paulista, São Paulo, v. 4, n. 1, p. 125-164, 1996. Disponível em: http://www. scielo.br/pdf/anaismp/v4n1/a14v4n1.pdf. Acesso em: 15 set. 2017.

APMOP. Arquivo Público Municipal de Ouro Preto, Fundo Câmara Municipal de Ouro Preto, Documentos Avulsos, Contratos de Melhoramento da Capital, Projecto de Boulevard para a cidade de Ouro Preto, 1891.

BENJAMIN, Walter. Magia e técnica, arte e política: ensaios sobre literatura e história da cultura. 7. ed. Tradução de Sérgio Paulo Rouanet. São Paulo: Brasiliense, 1994. (Obras Escolhidas, v. 1).

Rua de mão única. 5 ed. Tradução de Rubens Rodrigues Torres Filho e José Carlos Martins Barbosa. São

Paulo: Brasiliense, 1995. (Obras Escolhidas, v. 2). 
Passagens. Willi Bolle (Org.). Tradução de Irene Aron e Cleonice Paes Barreto Mourão. Belo Horizonte: UFMG; São Paulo: Imprensa Oficial do Estado, 2006.

BOTELHO, lura Breyner. Alberto da Veiga Guignard: o poeta das tintas. Instituto de Formação e Educação, 18 ago. 2014. Disponível em: <http://ife.org.br/alberto-da-veiga-guignard-o-poeta-das-tintas/>. Acesso em: 9 abr. 2018.

CAUQUELIN, Anne. Essai de philosophie urbaine. Paris: Presses Universitaires de France, 1982.

CHOAY, Françoise. A alegoria do patrimônio. São Paulo: Unesp, 2006.

CIRCUITO do Ouro Convention \& Visitors Bureau. Ouro Preto [Site Oficial de Turismo]. Disponível em: <http://ouropreto.org.br>Acesso em: 2 ago. 2018.

CUNHA, Nara Rúbia de C. Chão de Pedras, Céu de Estrelas: o museu-escola do Museu da Inconfidência, Ouro Preto, década de 1980. Dissertação (Mestrado em Educação) - Universidade Estadual de Campinas, Campinas. 2011. Disponível em: http://repositorio.unicamp.br/bitstream/REPOSIP/251279/1/Cunha_ NaraRubiadeCarvalho_M.pdf. Acesso em: 15 set. 2017.

Primaveras Compartilhadas: (re)significando a docência na relação com cidade, memórias e linguagens. Tese (Doutorado em Educação) - Universidade Estadual de Campinas, Campinas. 2016. Disponível em: <http://repositorio.unicamp.br/bitstream/REPOSIP/.../1/Cunha NaraRubiadeCarvalho D.pdf>. Acesso em: 9 abr. 2018.

FONTANA, Luiz. Liceu de Artes e Ofícios. Ouro Preto, [194-]. Arquivo Público Municipal de Ouro Preto, Coleção Luiz Fontana (sob a custódia do Instituto de Filosofia Artes e Cultura da Universidade Federal de Ouro Preto-Núcleo de Mentalidade e Memória).

GALZERANI, Maria Carolina Bovério. A produção de saberes históricos escolares: o lugar das memórias. In: FERREIRA, Antonio Celso; BEZERRA, Holien Conçalves; LUCA, Tania Regina de (Orgs.). O Historiador e seu tempo. São Paulo: Unesp, 2008. p. 223-235.

GAY, Peter. A experiência burguesa: da Rainha Vitória a Freud. A educação dos sentidos. São Paulo: Cia. das Letras, 1988.

KONDER, Leandro. O que é dialética? 12. ed. São Paulo: Brasiliense, 1985. (Coleção Primeiros Passos, n. 23).

KOSSOY, Boris. Fotografia e história. Cotia: Ateliê Editorial, 2012.

Realidades e ficções na trama fotográfica. Cotia: Ateliê Editorial, 2000.

LEMACNY, Jean-Claude. Metamorfoses dos olhares fotográficos sobre a cidade. Projeto História, São Paulo, n. 18, p. 115-120, jan./jun. 1999. Disponível em: https://revistas.pucsp.br/index.php/revph/article/ view/10982/8102. Acesso em: 15 set. 2017.

LEMOS, Celina Borges. O século XIX na paisagem cultural ouro-pretana. Cotidiano, arquitetura e modernidade imperial. In: SEMINÁRIÓ SOBRE A ECONOMIA MINEIRA, 12., 2006, Diamantina. Anais... Disponível 
em: <https://diamantina.cedeplar.ufmg.br/portal/download/diamantina-2006/D06A021.pdf.cedeplar. ufmg.br/seminarios/seminario.../2006/D06A027.pdf. Acesso em: 2 ago. 2018.

MARTINS, Alexandre Alvarez de Souza; DAMASCENO, Sueli (Orgs.). Referências: Ouro Preto em Luiz Fontana. 2. ed. Ouro Preto: Ufop, 1996.

MENDES, Murilo. Contemplação de Ouro Preto. Rio de Janeiro: Ministẹrio da Educação e Cultura, 1954.

MONDENARD, Anne de. A emergência de um novo olhar sobre a cidade. Projeto História, São Paulo, n. 18, p. 107-113, jan./jun. 1999. Disponível em: https://revistas.pucsp.br/index.php/revph/article/view/10981/8101. Acesso em: 15 set. 2017.

NATAL, Caion Meneguello. Ouro Preto: a construção de uma cidade histórica, 1891-1933. Dissertação (Mestrado em História) - Universidade Estadual de Campinas, Campinas, 2007. Disponível em: <http://repositorio. unicamp.br/bitstream/REPOSIP/279438/1/Natal_CaionMeneguello_M.pdf>Acesso em: 9 abr. 2018.

OLIVEIRA,Alexandre Augusto de. OOlhar Fotográficode Luiz Fontana: documentação de Ouro Preto (1930-1960). Fotografia e arte pública: um estudo de caso. 118p. Dissertação (Mestrado em Artes) - Universidadé Estadual de São Paulo, São Paulo. 2006. Disponível em: https://repositorio.unesp.br/bitstream/handle/11449/87007/ oliveira aa me ia.pdf?sequence=1\&isAllowed=y. Acesso em: 15 set. 2017.

PALHARES, Taisa Helena Pascale. Modernidade, tradição e carácter nacional na obra de Alberto da Veiga Cuignard. Tese (Doutorado em Filosofia) - Universidade de São Paulo, São Paulo, 2010. Disponível em: <www.teses.usp. br/teses/disponiveis/8/8133/tde.../2010_TaisaHelenaPascalePalhares.pdfs. Acesso em: 9 abr. 2018.

PROJETO GUICNARD. Secretaria Estadual de Cultura de Minas Gerais. Disponível em: http://www7.cultura. mg.gov.br/index.php?acao=busca ampliado\&nome $=$ cartao postal op\&endereco=documentos textuais ampliadas. Acesso em: 2 ago. 2018a.

Secretaria Estadual de Cultura de Minas Cerais. Disponível em: http://www1.cultura.mg.gov.br/index.php?acao=busca_ampliado\&nome=verso_cartao_op\&endereco=documentos_textuais_ampliadas. Acesso em: 2 ago. 2018b.

Secretaria Estadual de Cultura de Minas Cerais. Disponivel em: http://www1.cultura.mg.gov. br/index.php?acao=busca_ampliado\&nome $=1$ \&endereco=img_ampliadas $/ G \% 20$ SECMCC $\% 20$ 0024\&titulo=Paisagem. Acesso em: 2 ago. $2018 \mathrm{c}$.

SILVA, Fernando Pedro da; RIBEIRO, Marília Andrés; PRADO, Jacqueline (Orgs.). Guignard: depoimento. Belo Horizonte: C/Arte, 2015.

TRIPADVISOR BRASIL. Tripadvisor Brasil. Disponivel em: <http://www.tripadvisor.com.br> Acesso em: 2 ago. 2018.

VIDAL, Diana Gonçalves. Fontes visuais na história: significar uma peça. Varia História, Belo Horizonte, v. 10, n. 13, p.128-131, jun. 1994. Disponível em: <https://static1.squarespace.com/ static/561937b1e4b0ae8c3b97a702/t/572782de27d4bd23efdf7719/1462207199510/09_ Vidal\%2C+Diana+Concalves.pdf>. Acesso em: 9 abr. 2018. 